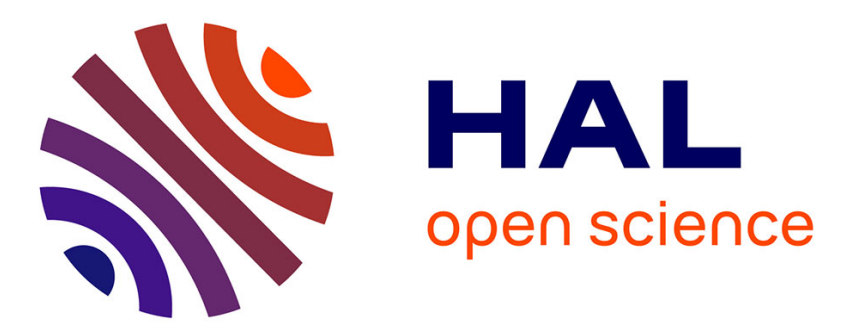

\title{
Application of the sum-peak and coincidence spectrometer to the determination of the absolute efficiency
}

G. Mallet

\section{- To cite this version:}

G. Mallet. Application of the sum-peak and coincidence spectrometer to the determination of the absolute efficiency. Journal de Physique Lettres, 1983, 44 (4), pp.147-150. 10.1051/jphyslet:01983004404014700 . jpa-00232156

\section{HAL Id: jpa-00232156 https://hal.science/jpa-00232156}

Submitted on 1 Jan 1983

HAL is a multi-disciplinary open access archive for the deposit and dissemination of scientific research documents, whether they are published or not. The documents may come from teaching and research institutions in France or abroad, or from public or private research centers.
L'archive ouverte pluridisciplinaire HAL, est destinée au dépôt et à la diffusion de documents scientifiques de niveau recherche, publiés ou non, émanant des établissements d'enseignement et de recherche français ou étrangers, des laboratoires publics ou privés. 


\title{
Application of the sum-peak and coincidence spectrometer to the determination of the absolute efficiency $\left({ }^{*}\right)$
}

G. Mallet

U.E.R. I.P.M., Université de Nice, Parc Valrose, 06034 Nice Cedex, France

(Reçu le 13 avril 1982, révisé le 2 juillet, accepté le 20 décembre 1982)

Résumé. - Nous montrons comment l'utilisation de deux détecteurs de $\mathrm{Ge}(\mathrm{Li})$ identiques, permet de tirer parti des pics d'addition pour déterminer l'efficacité absolue de détection des photocopies.

\begin{abstract}
We point out that the use of two identical Ge(Li) detectors allows us to take advantage
\end{abstract} of the parasitic summing effect to determinate the full energy peak efficiency.

Normally, in $\gamma$ spectra, we observe distributions due to the addition in the detector of pulses coming from gammas emitted in coincidence by the sample studied. Generally, this addition effect not only complicates the stripping of the spectra, but also impedes an accurate estimate of the transition intensities [1-2]. However, some authors did try to take advantage of this addition effect [3-5].

In previous publications [6-9], we have demonstrated that great improvements in the determination of the energy levels of radioisotopes by the sum-peak technique of coincidence counting have been achieved by the use of two identical $\mathrm{Ge}(\mathrm{Li})$ detectors. They are located on either side of the sample, and are associated with a coincidence unit. The aim of this work is to show that the determination of the absolute full energy peak efficiency (F.E.P.E.) is also possible using this technique.

Let us consider a nucleus having at least three excited levels, the deexcitation of which is sketched in figure 1 . It is easy to show [1,7-9] that the experimental intensities $S_{i j}$ and $S_{i j k}$ of the sum-peaks corresponding respectively to the simultaneous absorption of the gamma $i$ and $j$ and $i, j$ and $k$ are given by the following relations :

$$
\begin{aligned}
S_{i j} & =\frac{I_{i} \cdot I_{j}}{I_{N_{2}}} \cdot \varepsilon_{i} \cdot \varepsilon_{j} N \cdot T \cdot W . \\
S_{i j k} & =\frac{I_{i} \cdot I_{j} \cdot I_{k}}{I_{N_{3}} \cdot I_{N_{2}}} \cdot \varepsilon_{i} \cdot \varepsilon_{j} \cdot \varepsilon_{k} N \cdot T \cdot W,
\end{aligned}
$$

(*) La version française de cet article a été proposée aux Comptes Rendus de l'Académie des Sciences. 


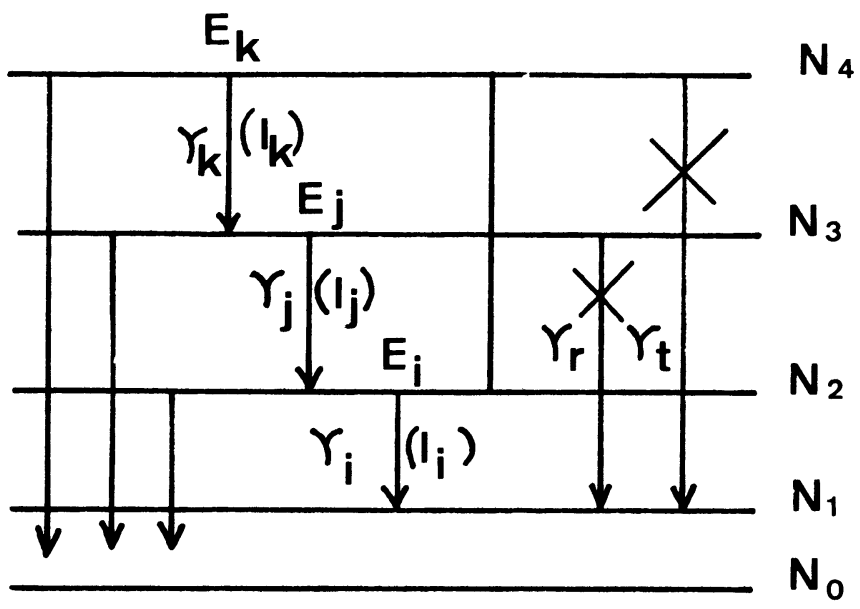

Fig. 1. - Example of a deexcitation mode allowing the determination of the F.E.P.E.

where : $I_{i}, I_{j}$ and $I_{k}$ are the intensities of $\gamma_{i}, \gamma_{j}$ and $\gamma_{k}$ respectively; $\varepsilon_{i}, \varepsilon_{j}$ and $\varepsilon_{k}$ are the F.E.P.E. at the energies $E_{i}, E_{j}$ and $E_{k} ; I_{N_{2}}$ and $I_{N_{3}}$ the intensities of the population of the levels $N_{2}$ and $N_{3}$ (Fig. 1); $N$ is the activity of the source; $T$ the duration of the experiment and $W$ a coefficient of angular distribution.

The ratio of (2) to (1) gives the F.E.P.E. at energy $E_{k}$ :

$$
\varepsilon_{k}=\frac{S_{i j k}}{S_{i j}} \cdot \frac{I_{N_{3}}}{I_{k}}
$$

As an application of the method we have measured, during the excitation of ${ }^{110} \mathrm{Cd}$ [10] (Fig. 2) the F.E.P.E. at $937.5 \mathrm{keV}$ of two identical $44.4 \phi \times 47.5 \mathrm{~mm}^{2}$ single-ended $\mathrm{Ge}(\mathrm{Li})$ detectors grown from the same Ge ingot. The detectors had an active volume of $70.5 \mathrm{~cm}^{3}$ and an energy resolution of $2.2 \mathrm{keV}$ at $1.33 \mathrm{MeV}$. The distance between the detector cases and the source was $10.0 \mathrm{~cm}$. Relation (3) allows us to write :

$$
\xi_{(937.5 \mathrm{keV})}=\frac{S_{2479.9 \mathrm{keV}}}{S_{1542.4 \mathrm{keV}}} \cdot \frac{I_{N(1542.4 \mathrm{keV})}}{I_{\gamma(937.5 \mathrm{keV})}}=0.0429 \pm 0.0012 .
$$

Measurements of peak areas of $2479.9(937.5+884.7+657.7 \mathrm{keV})$ and $1542.4 \mathrm{keV}$ $(657.7+884.7 \mathrm{keV})$ were performed sixty six times (during 800 hours) with a 8192 channel analyser (Hewlett-Packard 5401/B) during our study of the sum-peak and coincidence spectrum of ${ }^{110} \mathrm{Ag}^{\mathrm{m}+\mathrm{g}}$ [8], while $I_{N(1542.4 \mathrm{keV})}$ and $I_{\gamma(937.5 \mathrm{keV})}$ are the intensities, due to the results of Meyer's work $[11,12]$.

The extensive use of semi-conductor detectors in $\gamma$-spectrometry has led many authors to propose original experimental or theoretical methods for the absolute efficiency determination. Waibel et al. [13] have classified the experimental methods in four categories :

1) the simplest method needs calibrated $\gamma$-ray sources. The experimental photopeak efficiency of detection for a given $\gamma$-ray is evaluated [14] from measured data on the basis of the equation (4)

$$
\varepsilon=\frac{N}{A \cdot t \cdot I}
$$




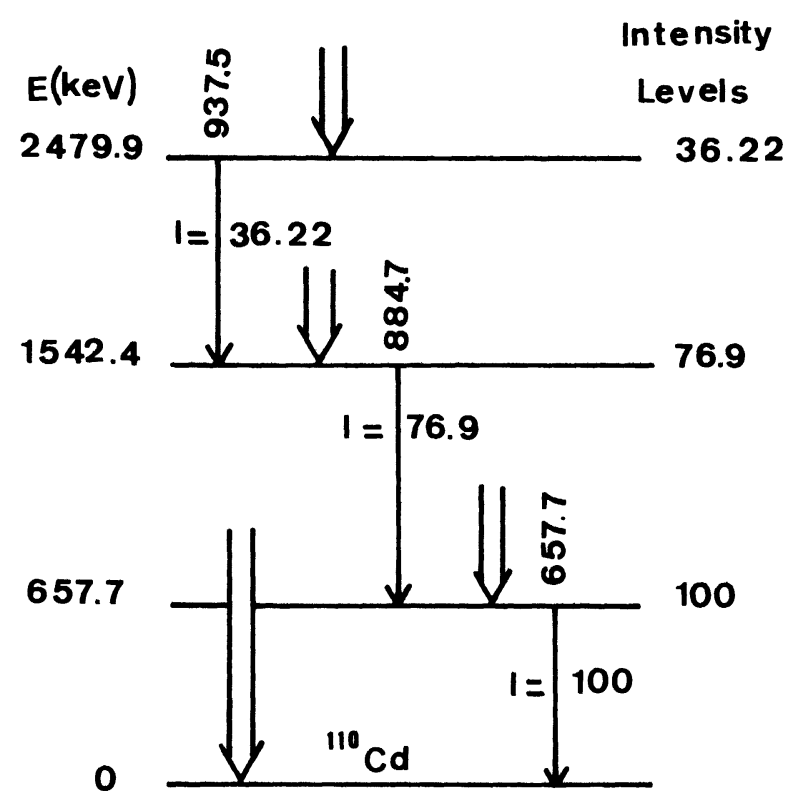

Fig. 2. - Partial level scheme of ${ }^{110} \mathrm{Cd}$.

where : $N$ is the number of detected pulses in the photopeak area, $A$ is the disintegration rate of the $\gamma$-ray source, $t$ is the counting time, and $I$ is the absolute intensity of the relevant $\gamma$-emission ;

2) for high $\gamma$-ray energies, well defined $\gamma$-ray sources produced by nuclear reactions are used. In this case, it is absolutely necessary to know the cross sections and the emission probabilities;

3) the coincidence method allows us to determine simultaneously the efficiency of the detector and the source strength;

4) above $1.022 \mathrm{MeV}$, relative efficiency determination is possible with a pair spectrometer, but the absolute efficiency determination requires a calibrated source.

The accuracy of $\mathrm{Ge}(\mathrm{Li})$ efficiency curves over the range 0.1-3.0 $\mathrm{MeV}$ obtained with these methods is generally contained between 0.5 and $5 \%$ [15-18].

Several authors have proposed semi-empirical formulae and analytical functions to represent the F.E.P.E. curves of the $\mathrm{Ge}(\mathrm{Li})$ detectors [19-21]. The validity of these relations has been tested successfully for a great range of detectors, the accuracy being related to a precise knowledge of the detector dimensions.

In addition to the fact that the suggested têchnique i.e. using the parasitic summing effect positively is easy to use when it is enlarged to the F.E.P.E. determination of one detector used in the single mode, we remark that in the chosen example the uncertainty is lower than $3 \%$ and consequently comparable to the previous methods.

\section{References}

[1] WaPSTRA, A. H., in $\alpha, \beta$ and $\gamma$-ray spectroscopy, ed. K. Siegbahn (North-Holland, Amsterdam) 1965, 539.

[2] Girgis, R. K. and Van Lieshout, R., Nucl. Phys. 12 (1959) 672.

[3] JASINSKI, A., LudZiejewski, J. and BialKowski, J., Nucl. Instrum. Meth. 31 (1964) 90. 
[4] Kantele, J. and Suominen, P., Nucl. Instrum. Meth. 86 (1970) 65.

[5] Hutchinson, J. M. R., ManN, W. B. and Mullen, P. A., Nucl. Instrum. Meth. 112 (1973) 187.

[6] Mallet, G. and Ythier, C., C. R. Hebd. Séan. Acad. Sci. B. 286 (1978) 183.

[7] Mallet, G. and Ythier, C., C. R. Hebd. Séan. Acad. Sci. B. 286 (1978) 211.

[8] Mallet, G., Thèse, Nice, 1978.

[9] Mallet, G. and Pravikoff, M. S., Nucl. Instrum. Meth. 184 (1981) 469.

[10] Mallet, G., Dalmasso, J., Maria, H. and Ardisson, G., J. Phys. G. 7 (1981) 1259.

[11] MeYer, R. A., private communication to Nucl. Data Sheets 22 (1977) 135.

[12] Mallet, G., J. Phys. Soc. Japan. 50 (1981) 384.

[13] WAIBEL, E. and GrosswendT, B., Nucl. Instrum. Meth. 131 (1975) 133.

[14] Cejnar, F. and Kovař, I., Int. J. Appl. Radiat. Isotopes 31 (1980) 79.

[15] Gehrke, R. J., Cline, J. E. and Heath, R. L., Nucl. Instrum. Meth. 91 (1971) 349.

[16] Ḿ Nelles, L. A. and CAMPBell, J. L., Nucl. Instrum. Meth. 109 (1973) 241.

[17] Abreu, M. C., Maio, A. A. and Temes D'Oliveira, M. J., Nucl. Instrum. Meth. 123 (1975) 295.

[18] Helmer, R. G., Nucl. Instrum. Meth. 193 (1982) 87.

[19] Griffiths, R., Nucl. Instrum. Meth. 91 (1971) 377.

[20] SinGH, R., Nucl. Instrum. Meth. 136 (1976) 543.

[21] BambleVSKII, V. P., Instrum. Exp. Tech. (U.S.A.) 22 (1979) 362. 